even in such details as the quotation of literature; the names of American authors who have added refinoment to an existing theory are included, while those of the originators are omitted. Apart from these minor objections, the book can be warmly recom. mended.

\section{Elementary Survey of Physics}

A Non-Mathematical Presentation, with \& Special Supplement for Pre-Medical Students. By Prof. Arthur E. Haas, with the collaboration of Prof. Ira M. Freeman. Pp. $\mathrm{x}+20 \%$. (I,ondon: Constablo and Co., Ltd., 1939.) 7s. $6 d$. net. IHERE is a tendency to-day to impart a general
acquaintance with physical science to students
outside this field; even those in the college of liberal
arts are now taught the elements of physical science
as part of their general culture. A serious difficulty
arises from the antipathy on the part of most
students, including pre-medical students, to the
application of mathematical methods. Prof. Haas has
presented a survey of physics without introducing
mathematics except of the most elementary nature.
In spite of the absence of mathematics, the field
covered is comprehensive, and the explanations are
so lucid that no one need be deterred by the fear of
failure to understand the physical picture of Nature
delineated by the author.
There are two appendixes. The first deals with
the more important applications of physics to
medicine, especially in such fields as light therapy,
electrothorapy, radium therapy, etc. The second
appendix supplies a number of elementary formula
which can be applied by anyone with only a very
meagre mathematical equipment. It may be safely
predicted that the work will commend itself to a
large number of students, and the general public too
will find it nost readable.

\section{PSYCHOLOGY}

Introduction to Psychology

By Edwin Garriques Boring, Herbert Sidney Langfold, Harry Porter Weld and Collaborators. Pp. xxii +652. (London: Chapman and Hall, Ltd.; New York : John Wiley and Sons, Ltd., 1939.) $15 s$. net.

T T has been generally felt for many years that the 1 writing of an up-to-dato text-book on psychology required specialized knowledge of so many branches of the subject that it was beyond the power of any one man. Two or three years ago, threo distinguished American psychologists, with the help of a number of collaborators, produced "Psychology : a Factual Textbook", which was very generally welcomed as a satisfactory text-book for courses in Great Britain also. As a result of the numerous suggestions they received from users of the book, they have now produced a new edition so radically different that they have given it a new title.

Their earlier edition followed the conventional order of treatment in which sensation and perception came first and led up to problems of personality and social psychology at the end. They have now made the bold innovation of reversing this order. They have felt that much of the treatment of sensation and perception, about which relatively much is known, can with advantage be left to specialist courses. Also they have thought it an advantage to start with the functioning of the organism in the social environment, about which the student has more previous knowledge than he has of sensory functions. This is no doubt true, but this method of approach sacrifices the ad. vantage of beginning with a part of the subject on which there is much exact scientific knowledge.

The previous edition proved itself a satisfactory text-book. It was up to date, accurate and eclectic. In its now form, with additional matter and an increased number of collaborators, it appears to have sacrificed none of these merits. It should prove to be as satisfactory as its predecessor. Whether the new order of presentation is the better can only be told by trial.

R. H. THOUless.

\section{Children with Delayed or Defective Speech}

Motor-Kinesthetic Factors in their T'raining. By Sara M. Stinchfield and Edna Hill Young. Pp. xvi+174. (Stanford University, Calif. : Stanford University Press; London : Oxford University Press, 1938.) 14s. not.

THIS most useful book describes the theory and practice of the Hill Young School of Spoech in Los Angeles. It is divided into two parts, the first by Dr. Stinchfield, discussing the problem to be solved in dealing with children with delayed or defective speech, and the second by Mrs. Young, dealing with the practical side.

It is estimated that there are four million children in the United States handicapped in the use of speech.

Tho treatment consists briefly in training muscular action for whole words. There is a liberal supply of photographs showing how the child is taught to use his muscles in the enunciation of the various words used.

Man against Himself

By Karl A. Menninger. Pp. xii +485 . (London, Bombay and Sydney : George G. Harrap and Co., Ltd., 1938.) 15s. net.

T. I. A. MENNINGER, who some yoars ago produced an excellent book, "Tho Human Mind", has given us a very interesting book on somo of the wider implications of suicide in "Man against Himself".

The book is largely based on psycho-analytical principles. After a brief consideration of suicide as commonly understood, the author deals with what he calls chronic suicide, which includes asceticism, neurotic invalidism and alcoholic addiction, and then with focal suicide, which includes mutilations, purposive accidents, impotence and frigidity and polysurgery.

The treatment consists in self-reconstruction, dealing with the aggressive, self-punitive and erotic motivations. 